\title{
Cuando el fútbol dejó de ser deporte. Reflexiones
}

When football stopped being a sport. Reflections.

\author{
Dr. Francisco José MONTES FERNÁNDEZ \\ Ex-profesor Universidad Complutense \\ fjmontes@telefonica.net
}

\begin{abstract}
Resumen: El fútbol ha dejado de ser un deporte para ser un negocio como tantos otros, donde, como en las fábricas o en los consejos de administración, se valora a los hombres como si fueran cosas, en función de los beneficios que de ellos se puedan obtener para alcanzar el máximo rendimiento económico, al margen de cualquier pensamiento de tipo moral o humano, dejando de lado su libertad como personas.
\end{abstract}

Abstrac: Soccer has ceased to be a sport to be a business like so many others, where, as in factories or on boards of directors, men are valued as if they were things, based on the benefits that can be obtained from them to achieve maximum economic performance, regardless of any moral or human thinking, leaving aside their freedom as people.

Palabras clave: Deporte, Fútbol, Economía, Europa, Derechos Humanos, Moral, Violencia, Medios de comunicación social, Familia, Niños, Infancia, Padres.

Keywords: Sport, Football, Economy, Europe, Human Rights, Morals, Violence, Social Media, Family, Children, Childhood, Parents.

\section{Sumario:}

I. Introducción.

II. Situación económica y cultural de España: Sinopsis.

III. La compraventa de jugadores. 
IV. La violencia en el futbol.

V. Los derbis.

VI. La nefasta influencia de los antiguamente llamados medios de comunicación social.

VII. Las redes sociales.

VIII. Conclusiones

IX. Apéndices.

Recibido: octubre 2021.

Aceptado: diciembre 2021. 


\section{INTRODUCCIÓN}

No sé si la solidaridad, la preocupación por los demás, las ganas de ayudar a los que menos tienen se hereda o nace con uno mismo. El caso es que yo desde muy pequeño siempre tuve una preocupación constante por los demás que ha llegado hasta la actualidad. Nunca lo vi en mi entorno. Es por ello que he hecho de todo en relación con los demás. Empecé integrándome en una congregación mariana que entonces dependía de los jesuitas del Pozo de Madrid, que era el Pozo del tío Raimundo y en Palomeras bajas (hoy felizmente no queda nada de aquello y hay unas grandes moles de pisos que en nada se parece al barrio de la Concepción, diseñado por José Banús gran amigo de Franco y sus camarillas). En aquellos barrios se hizo yo creo mundialmente famoso el P. Francisco García Salve y otros de los que no recuerdo su nombre. Allí íbamos todos los sábados y domingos con el dinero que recaudábamos durante la Navidad en la confluencia de las calles Goya y Serrano, cuando todavía estaba la Casa de la moneda. Íbamos con comida y ropa que comprábamos en El Corte Inglés por ser más cómodo y facilitarnos grandes bolsas para poderlos trasportar; los alimentos en las proximidades donde también comprábamos los elementos de construcción para levantar chabolas con materiales más sólidos que el cartón o las chapas, evitando así la entrada del viento por todos los lugares. No olvidemos que allí podían vivir 4 o 5 personas y un animal, por lo general un burro o asno que les permitía recoger chatarra o similares y realizar transportes que era de lo que malvivían. En el centro de la chabola había una estufa que servía para dar calor y cocinar con carbón, si era posible, o al menos leña.

\section{SITUACIÓN ECONÓMICA Y CULTURAL DE ESPAÑA: SINOPSIS}

La cadena de efectos socioeconómicos que genera esta política del mercado libre en el mundo del deporte, especialmente en el área del futbol, es brutal. Los defensores acérrimos de la mano invisible de Adam Smith no admiten que se puedan poner puertas al campo, puesto que todo llega de forma natural al equilibrio entre la oferta y la demanda. No obstante, existen límites morales, éticos o como queramos llamarlos por los que debemos proteger unos valores sociales y culturales básicos sobre los que alcanzar un mínimo de justicia. 
El mercado del futbol, es lo que es, se nos ha ido de las manos generando más desigualdades y no solo entre los elegidos para protagonizar el espectáculo y el resto de la sociedad, sino entre los propios aficionados, entre quienes, en principio, deberían constituir un público uniforme.

Me explico: a finales del XIX comienza a incorporarse la compraventa al deporte del futbol. La razón es obvia: la industrialización genera una clase social urbana que reclama la necesidad de cubrir ciertos intereses culturales que satisfagan a una cada vez mayor masificación humana sin medios para financiarse más allá de las necesidades esenciales del día a día.

Ya tenemos, por tanto, dos elementos pilares: masificación-necesidad de distracción sin tener capacidad económica individual.

A partir de ese momento, la bola de nieve se va agrandando, desbocando... Lo que surgió para distraer a un público homogéneo ha acabado por convertirse en un medio discriminatorio, en una maquinaria de hacer dinero movida por los hilos de los intereses crematísticos de unos pocos.

Lo curioso de esta injusta realidad es que ninguno de los actores que intervienen en ella está descontento, ya que todos y cada uno de ellos obtiene pingües beneficios, bueno, todos todos... En un principio, un público más o menos homogéneo se distraía y disfrutaba viendo la rivalidad de dos equipos de futbol. Los dos actores primigenios (público y equipos) intervenían para el disfrute de ambos. Los individuos quedaban absorbidos por la pluralidad. Sin embargo, se empezaron a incorporar intereses económicos: apuestas, derechos de imagen, publicidad, merchandising...Los equipos se han ido diluyendo para convertirse en la suma de jugadores de distintos precios. Los clubes, por su parte, se han transformado en entidades mercantiles y, como tales, su única finalidad es la obtención de beneficios. Se ha potenciado el interés público por ese espectáculo a base de inyectar en el torrente sanguíneo de la sociedad la rivalidad, no como elemento natural de toda competición deportiva, sino como casus belli y, por tanto, justificante para digerir cualquier exceso. La publicidad, las comisiones, las exclusividades en materia de retransmisión audiovisual, los derechos de imagen, los patrocinios...todo nos empuja a aceptar al monstruo en el que hemos convertido el mundo del futbol. Si, efectivamente, podemos hablar del mundo del futbol porque la globalización en la que nos encontramos inmersos como consecuencia del avance en las comunicaciones, ha llevado a este negocio de la pelota a alcanzar dimensiones inabarcables que se derraman e impregnan la sociedad de consumo.

Pero ¿qué pasa con la finalidad última de éste deporte: el disfrute del público? ¿Es que, acaso, no sigue sirviendo para lograr la más sana y homogénea 
satisfacción de quienes actúan como sujetos pasivos de este negocio-deporte? Creo que la respuesta es: rotundamente NO. La propia maquinaria futbolística de hacer dinero se ha colado por las rendijas del público, creando nuevas distinciones que colaboran para crear más diferencias sociales.

En efecto, quienes constituimos el inmenso grupo de potenciales espectadoresconsumidores del producto ya no somos una homogénea agrupación de aficionados al deporte, sino que pasamos a integrar distintas categorías: quienes pueden acceder al espectáculo personalmente, pagando, claro; quienes pueden presenciarlo sin restricciones a través de los medios de comunicación, pagando, por supuesto; y quienes se conforman, por falta de medios, con contemplarlo a toro pasado mediante una grabación enlatada o una crónica redactada en un periódico. A nadie salva la extensa sombra del monstruo.

Con este breve estudio intento mostrar el panorama del negocio del futbol a través de las cifras oficiales o públicas a las que he podido acceder y desde una perspectiva afín a fomentar toda actividad cultural social. Con este último filtro indicado, mi vocación natural por todo aquello que constituye la Cultura (con mayúscula), debo concluir con el horror que despierta la contemplación actual del futbol.

Viene a cuento porque teniendo en cuenta la situación cultural y económica de España no parece que sea moralmente aceptable las cantidades que se pagan por los jugadores de fútbol cuando tantos millones de personas sufren carencias básicas, de acuerdo con las últimas estadísticas de elDiario.es el pasado 6 de octubre de $2021^{1}$ :

La pandemia ha tenido un impacto "desolador" en la sociedad española, con 11 millones de personas en exclusión social y, de ellas, 6 millones ya en situación de pobreza severa. Son 2 millones más que en 2018 y supone la cifra más elevada registrada en el país desde 2007. Es la radiografia que Cáritas y la Fundación Foessa han mostrado (...) en el informe "Sociedad expulsada y derecho a ingresos", que alerta del "ensanchamiento del espacio de la exclusión social, donde viven ahora 2,5 millones de personas nuevas respecto del año 2018", de ellas casi 2 millones en exclusión severa. Necesitamos hacer una llamada de atención a la sociedad de que la crisis nos deja un impacto desolador y muy preocupante; esta crisis deja tras de si una profunda huella con importantes consecuencias en las condiciones de vida y niveles de integración social de personas y familias, cuyas consecuencias seguirán

\footnotetext{
${ }^{1}$ EFE, 6 de octubre de 2021, 14:00horas. Consultado el 9 de octubre de 2021.
} 
agravándose mientras continúe la pandemia y, previsiblemente, más allá", ha alertado el técnico del equipo de estudios Thomas Ubrich. Según el informe, se aprecia un empeoramiento generalizado de los niveles de integración para el conjunto de la población: han aumentado las familias en situación de pobreza, pero también se han reducido los hogares sin problemas de exclusión, que son del $41,2 \%$ cuando en 2018 eran el $49,3 \% .^{2}$

Se sigue incrementando el número de familias para quienes los gastos de la vivienda suponen una carga tal que, una vez realizados éstos, se quedan en situación de pobreza (...) a día de hoy vive el 14\% de los hogares ${ }^{3}$ en esta situación.

El Salario Mínimo Profesional (SMI) desde el 1 de septiembre de 2021 es de $965 €$ mensuales.

En el año 2017 el traspaso de Neymar del F. C. Barcelona al Paris-Saint Germain F.C. se estableció en 222 millones de euros.

Sobre la situación cultural en España, la Asociación para la Investigación de Medios de Comunicación (AIMC), entre 1.850 entrevistas realizadas entre el 30 de abril al 26 de mayo, concluyó que el $16 \%$ de los españoles no lee nunca o casi nunca porque no le gusta o no le interesa. El 33\% no compró ni un libro y el 7\% solo adquirió ebook. Entre los temas, la novela se llevó la palma. ¿Puede pensarse que con este nivel de lectura podemos generar personas capaces de reflexionar adecuadamente para gestionar su propia vida y la de su familia en los ambientes que, sin duda, son verdaderamente hostiles por la falta del espacio mínimo en el hogar para sobrevivir? Frente a esta situación nos encontramos con las fotografías de los jugadores más importantes de futbol en sus magníficas mansiones, con lujosísimos coches, bellísimas mujeres, aviones privados y frecuentes vacaciones de lujo, además de las ropas más costosas de marca que se puedan encontrar en las principales capitales del mundo.

¿Es éste un nivel lógico de convivencia entre clases sociales tan manifiestamente desiguales?

Realmente por dar patadas a un balón, con los entrenamientos y preparación física que se requiere para la práctica de este supuestamente denominado deporte,

\footnotetext{
${ }^{2}$ La pandemia dispara la pobreza severa en España y alcanza ya a seis millones de personas, la cifra más alta desde 2007. https://www.eldiario.es/economia/pandemia-dispara-pobrezasevera-espana-alcanza-seis-millones-personas-cifra-alta-2007_1_8372810.html. Consultado el 7 de octubre 2021.

${ }^{3}$ Ob. Cit.
} 
comparable al trabajo de un médico que salva vidas con un salario tan exigüo y jugándose, en muchos casos, su propia vida, como hemos visto con la reciente pandemia del COVID-19, parece radicalmente no solo injusto, sino inmoral, inadecuado y que no va a permitir nunca elevar el nivel cultural e intelectual de este país, sobre todo en este momento que se ha puesto en el candelero el hablar de la evasión de intelectuales, investigadores, cabezas pensantes, con imaginación y capacidad de inventiva y con metodología sobre la investigación.

Estas ideas nos conducen a pensar si realmente estamos valorando adecuadamente, en la sociedad actual, el trabajo de cada persona por el esfuerzo que requiere y los conocimientos que precisa.

Los museos más visitados de España ${ }^{4}$, nos da idea de lo que demanda la sociedad tanto de turistas españoles como foráneos, para que nos demos ideas de lo que demanda la sociedad actual:

1.- Museo del Prado (Madrid).

2.- Museo Reina Sofía (Madrid).

3.- Museo Dalí (Figueras, Gerona).

4.- Camp Nou Experience (Barcelona).

5.- Museo Guggenheim (Bilbao).

6.- Thyssen-Bornemisza (Madrid).

7.- El Tour del Bernabeu (Madrid).

8.- Museo Artes y Ciencias (Valencia).

Los museos más visitados de Madrid en 2020 fueron $^{5}$ :

1.- Reina Sofía.

2.- Museo del Prado.

3.- Museo del Real Madrid.

4.- Matadero.

5.- Centro Centro.

6.- Museo Thyssen-Bornemisza.

7.- Museo Arqueológico Nacional.

8.- CaixaForum.

9.- Casa-Museo Sorolla.

10.- Museo de Historia.

11.- Templo de Debod.

\footnotetext{
${ }^{4}$ Los museos más visitados de España. 17 enero 2017. http://www.elguialocal.es/es/blog/ 56/museos-visitados-espana/. Consultado 6 octubre 2021.

${ }^{5}$ Estos fueron los museos más visitados de Madrid en 2020. Madrid secreto. 18 abril 2021. https://madridsecreto.co/museos-mas-visitados-2020/. Consultado 6 octubre 2021.
} 
Los 10 mejores museos de fútbol del mundo:

1.- Museo del Real Madrid (España).

2.- Museo River (Argentina).

3.- Museo de la Pasión Boquense (Argentina).

4.- Museo del Camp Nou (España).

5.- Museo del Fútbol Sudamericano (Paraguay).

6.- Salón de la Fama del Fútbol (México).

7.- Museo del Fútbol (Uruguay).

8.- Old Trafford Museum (Inglaterra).

\section{LA COMPRAVENTA DE JUGADORES}

Los clubes de futbol han dejado de ser asociaciones deportivas para convertirse en sociedades mercantiles cuyos objetos de transacción son personas, concretamente jugadores de futbol, que son cosificados, pasando a ser simples mercancías, como una manufactura o un bien industrial o un edificio, tal es el caso del equipo francés de futbol, Paris Saint-Germain (PSG), propiedad de la sociedad Qatar Investment Authority, es decir del emir catarí Tamin bin Hamad Al-Thani que, además, impone un código ético para que sus jugadores sean amables y educados con los aficionados, con los que deben confraternizar. Tampoco pueden hacer manifestaciones ni realizar declaraciones sobre temas de propaganda política o religiosa que puedan menoscabar la imagen del club...catarí. En el caso de Neymar, si cumple con estas normas, recibirá mensualmente un bono de $541.680 €$.

Seguidamente se incluyen los cuadros de Wikipedia: Los fichajes más caros y Progresión histórica de compra de jugadores ${ }^{6}$ que por su anchura no caben en el texto, con los siguientes 3 párrafos transcritos de la misma página:

La mayoría de los fichajes más caros de la historia los han realizado clubes afiliados a la UEFA, y dentro de esta entidad, por clubes situados en la Eurozona o en el Reino Unido. El orden por defecto de la siguiente tabla muestra el montante del fichaje en euros corrientes, sin tener en cuenta la inflación. Por la existencia de fluctuaciones en el tipo de cambio, el orden puede no ser el mismo en libras. Los traspasos que tuvieron lugar antes de la adopción del euro se muestran en un montante

\footnotetext{
${ }^{6}$ Anexo: Fichajes más caros de la historia del fútbol y progresión histórica:

https://es.wikipedia.org/wiki/Anexo:Fichajes_m\%C3\%A1s_caros_de_la_historia_del_f $\%$ C3\%BAtbol.
} 
aproximado en euros. La lista enumera los cincuenta traspasos más valiosos del fútbol profesional.

Hay tres jugadores que aparecen dos veces en la lista: Neymar, Cristiano Ronaldo, y Ángel Di María. Romelu Lukaku lo hace tres veces. Todos los jugadores de la lista tienen su origen en Europa (UEFA), Sudamérica (CONMEBOL), Norteamérica (CONCACAF) o África (CAF). Después del traspaso de Christian Pulisic de CONCACAF en 2019, Asia (AFC) y Oceania (OFC) son las únicas confederaciones sin jugadores en la lista.

Actualizado a agosto de 2021

$\square E l$ fichaje rompió el récord de traspaso más caro a nivel mundial en su momento.

$\square$ El fichaje rompió el récord por un futbolista juvenil en su momento (menor de 20 años).

El fichaje rompió el récord nacional de la Liga del club de destino.

El fichaje rompió el récord por un futbolista sudamericano.

El fichaje rompió el récord por un futbolista africano.

El fichaje rompió el récord por un futbolista norteamericano.

El fichaje rompió el récord mundial por un portero.

El fichaje rompió el récord mundial por un defensa.

La supresión del futbol como deporte para convertirse en un negocio, da idea de que la mayoría de los campos de futbol se han rodeado de tiendas, propiedad de los equipos, que hacen además negocio con el merchandising de todos los objetos imaginables con el emblema del club y sus jugadores.

También son notabilísimos, en unos clubes más que en otros, los museos que se han constituido con los trofeos, recuerdos, fotografias, vídeos, etc. relacionados con el club, de forma que, por ejemplo, el Tour del Bernabeu se ha convertido en un museo con una media superior al millón de visitantes que lo convierte en el tercer museo más visitado de Madrid, incluso por delante del Thyssen Bornemisza. Tampoco se queda atrás el museo de F.C. Barcelona que, en la actualidad, es el estadio con mayor capacidad de Europa, próximo a los 100.000 espectadores, y uno de los más grandes del mundo.

La primera compraventa de jugadores de futbol se realizó en 1893 del futbolista Willie Groves que jugaba en el West Bromwich Albion al Aston Villa. El fichaje supuso, con la inflación ajustada a 3 de agosto de 2017, unos 13.250\$ USA.

La siguiente venta se realizó en 1903 y desde entonces ha continuado, con pequeños saltos, hasta la Primera Guerra Mundial, entre 1914 y 1918, aumentando 
de forma muy importante el precio de dichos jugadores, cuya compra se suspendió nuevamente entre 1932 y 1949, como consecuencia de la Segunda Guerra Mundial, llegando hasta nuestros días con la monstruosa cifra de 222 millones de euros por el citado fichaje de Neymar.

Estas comparaciones, como se dice vulgarmente, son odiosas porque existen numerosas dificultades para las equiparaciones económicas entre unos y otros países por el distinto cambio de divisas y las inflaciones en cada uno de los países que, en algunos momentos, fueron muy notables.

Otro dato importante son las comisiones por un fichaje, puesto que pueden alcanzar los 60 millones de euros y es, evidentemente, un buen motivo para realizar el cambio a otro club.

\section{LA VIOLENCIA EN EL FUTBOL}

La violencia en la sociedad actual se produce en todos los ámbitos de la vida y, aunque debería parecer paradójico por una supuesta mayor educación en todos los jóvenes, en lugar de reducirse parece que aumenta, sobre todo en los menores de edad que ya participan con frecuencia, no solo en hechos delictivos, sino en hechos con resultado de muerte.

Personalmente opino que el hecho de suprimir la mili obligatoria ha contribuido a que las nuevas generaciones no conozcan el sentido de la palabra disciplina y nada tiene esto que ver con el fascismo, sino con el orden entendiendo por tal no llegar tarde a las clases o al trabajo porque se me han pegado las sábanas, respetar el mobiliario urbano incluyendo los contenedores de plástico, semáforos, señales de circulación, etc. que pueden originar efectos graves y no deseados y pongo un ejemplo real. Siempre me ha gustado y disfruto porque no solo creo que hago bien, sino que puedo contribuir a evitar accidentes o similares y eso me hace sentirme no solo bien sino mejor, para compensar los quebraderos de cabeza que me han dado siempre, sin excepción, determinados empleados públicos y sobre todo muchos empleados de la mayoría de los bancos, personas con pocos escrúpulos y que han sido capaces de inducir a bastantes clientes (incluyendo ancianos y personas sin preparación) en la adquisición de productos financieros de dudosa calificación para aumentar los beneficios de su consejo de administración y sus directivos. La propia dinámica bancaria ha ido desplazando a una inmensa cantidad de ciudadanos que bien por su edad, bien por falta de medios, no alcanzan el nivel mínimo exigido para desenvolverse con seguridad en las operaciones más elementales de la vida económica. 
No resulta muy realista que todos los clientes bancarios tengan que saber informática por el llamado arte del birlibirloque y manejar las máquinas de los bancos o disponer de ordenador en sus hogares, etc., etc., solo con la finalidad de aumentar sus ingresos y enviar más empleados al paro aunque bien merecido se lo tienen en muchos casos por el mal trato, pésimo en algunas ocasiones, con que tratan estos empleados a los ancianos. ¿Tendrán padres, madres y abuelos? Pues bien, paseando un día por una calle de un solo sentido, vi que faltaba la señal en el cruce con otra que era de subida solamente, concretamente cruce de Claudio Coello con Jorge Juan en Madrid, y observé que algunos coches bajaban por Jorge Juan encontrándose de cara y a una cierta velocidad con los que subían desde Colón hacia Velázquez. Inmediatamente llamé a la Policía Municipal y al cabo de un momento recibí una llamada de la citada policía que me preguntaba sobre la gravedad y urgencia de mi demanda. Volví a comunicar que se producían giros indebidos y el problema de volver hacia atrás de los coches que habían invadido, bajando indebidamente, el carril de subida y comprendieron el problema e inmediatamente mandaron colocar la señal correspondiente, ya que la anterior había sido o arrancada por el golpe de un automóvil o por algún desaprensivo sin tener clara conciencia de que: primero, ese mobiliario lo pagamos todos los madrileños con nuestros impuestos; y segundo, que es un gasto inútil, perjudicando a otros más necesarios y que veces hay que dejar de realizar por falta de fondos.

No quiero yo decir que tenga que reimplantarse la mili, pero si unos meses, quizá tres o seis, para reducir el paro y, sobre todo, para que aprendan a vivir en sociedad algunas personas que no parece que tengan un espíritu muy sociable, en muchos casos por abuso de alcohol y drogas, jóvenes que tiene el puño muy suelto para darle un puñetazo al primero que tienen en frente y a veces con resultados no deseados, como la muerte del agredido, hecho que, por muchos años que te condenen a penas de cárcel, no tienen reparación posible, máxime cuando el propio ejercicio de la abogacía ayuda a suavizar la pena, dejando el amargo sabor al tener que digerir que el propio sistema que hemos implantado para defendernos de las agresiones, nos lleva a concluir que la muerte sale muy barata.

No quiero hablar de la violencia sexual y recordar al Prenda que ahora confiesa, quizás como argucia procesal, que efectivamente violaron en grupo a la joven que por activa y por pasiva acusaron de mentirosa con esa prepotencia que espero y deseo que la cárcel reduzca, aunque lamentablemente vemos muchos casos en los que la prisión no cumple el efecto para el que fue concebida: la rehabilitación del preso y su reinserción social.

Y todo esto viene a cuento de lo fácil que es matar a un niño con una bengala que le explota en el pecho, lo baratas que son éstas y lo fáciles de introducirlas 
en la ropa interior en un acontecimiento del tipo que sea y donde se usen indebidamente. Para evitarlo en la medida de lo posible, España firmó el: Instrumento de ratificación del Convenio del Consejo de Europa sobre un planteamiento integrado de protección, seguridad y atención en los partidos de fútbol y otros acontecimientos deportivos, hecho en Saint-Denis el 3 de julio de 2016 $6^{7}$, ratificado por España el 23 de mayo de 2017, entrando en vigor el 1 de noviembre de 2019.

Aunque los clubes europeos saben que incurren en fuertes multas, los equipos locales no quieren -pienso yo- o no pueden -dicen ellos para justificarse- controlar el acceso de estos artefactos a los campos de juego y en los alrededores, ámbito espacial también incluido en la norma restrictiva.

Los partidos de futbol donde estos fenómenos se suelen producir generalmente son los grandes acontecimientos tipo Champions League, finales de Copa, Europa Ligue, derbis..., ahora, desde hace unos años, también en la salida del hotel y la llegada al campo y a la vuelta, en los alrededores del campo, etc. Son siempre situaciones en los que la solución es muy complicada y las autoridades, tanto futbolísticas como gubernativas y locales, están intentando controlar, aunque personalmente lo veo muy complicado y para ello están llenando de cámaras de televisión con muy alta definición los interiores de los campos y las zonas que rodean los campos de futbol, para evitar incidentes como el tan reciente del pasado sábado 9 de octubre en los alrededores del campo del Oviedo, el Carlos Tartiere, donde hubo lanzamientos de bengalas y de objetos de todo tipo contra la Policía Nacional, a pesar de la gran cantidad de uniformados que cubrieron los alrededores del campo. Siempre son numerosos los ciudadanos que sufren agresiones o destrozos en el mobiliario de escaparates, portales y mobiliario urbano, cuando nada de eso beneficia a nadie absolutamente y crea una indignación entre los no simpatizantes del fútbol y la ciudadanía en general. Así lo reflejó la prensa del día siguiente y los periódicos digitales ya desde que se produjeron los hechos.

Lamentablemente estos actos vandálicos, porque no se los puede denominar de otra manera, no aportan nada positivo al futbol como deporte y crean un clima de inseguridad entre aficionados y público en general, además de entre los miembros de los equipos de futbol y sus directivos. Sin embargo, son frecuentes y me atrevería a decir que cotidianos en toda Europa y parte de EEUU y América del Centro y del Sur, hasta el punto de que no concebimos un partido sin calificarlo en alto o bajo, según el riesgo potencial que entrañe para el colectivo.

\footnotetext{
${ }^{7} \mathrm{BOE} \mathrm{n}^{\mathrm{o}} 252,19$ de octubre de 2019, p. 115151 a 115164.
} 
Entre los materiales considerados prohibidos para pasar por los espectadores en un acontecimiento deportivo y, por supuesto, en un partido de futbol, se especifican expresamente el material pirotécnico: bengalas, botes de humo, petardos, cohetes, etc., que son altamente peligrosos por ser utilizados por personas que no los saben manejar, ni lanzar o disparar y, repito, todos ellos están prohibidos desde el pasado 1 de noviembre de 2019. Pese a que, casi han transcurrido dos años desde que se adoptaron formalmente estas medidas preventivas, parece que proliferan más que antes de la prohibición. Es muy fácil solicitar mano dura de las autoridades competentes, pero por más medios coercitivos que se pongan a priori, no se puede abordar la seguridad en un encuentro de futbol partiendo de la presunción de culpabilidad de todos los asistentes al acto. En la memoria de todos están hechos tan doloroso como:

la tragedia de Heysel los sucesos acontecidos el 29 de mayo de 1985 en el Estadio de Heysel de Bruselas, en Bélgica, en el que murieron 39 aficionados (32 italianos en su mayoría seguidores de la Juventus, cuatro belgas, dos franceses y un británico) a causa de una avalancha de aficionados en los prolegómenos de la final de la Copa de Europa (hoy Liga de Campeones de la UEFA) entre el Liverpool y la Juventus de Turín, provocados por un incidente entre los aficionados más radicales del club inglés y un grupo de espectadores en su mayoría seguidores del equipo italiano. Los sucesos causaron, además, 600 heridos de diversa consideración. La tragedia sucedió solo dos semanas después de la tragedia de Valley Parade, con 56 muertos. La UEFA aplicó una sanción sin precedentes en el mundo del fútbol a raiz de la tragedia, imponiendo un veto de cinco años de toda competencia europea a todos los clubes ingleses, con el doble del castigo para el Liverpool aunque al final el club le fue rebajado el castigo a seis años; además de que el estadio de Heysel fue clausurado para partidos de fútbol, hasta su posterior demolición y reconstrucción ${ }^{8}$.

Hay que recordar que, según los pirotécnicos profesionales, hay que usarlas (las bengalas) a 10 metros de otra persona, algo imposible en un estadio Comprarlas es muy fácil en internet $\mathrm{y}$, por lo general, todas las personas que hacen uso de estos artefactos saben como comprarlos y al más bajo precio. No quiero hacer propaganda de nada, pero entrando en: https://ultrasshop.top/ Regulations, radicada en Polonia y con todas las instrucciones en castellano, podemos adquirir material pirotécnico fácilmente. Los pagos se pueden realizar de 7 maneras diferentes y la producción de los artículos es de 3 días; el precio de las llamadas fuentes de humo de distintos colores suele ser de $6 €$ y duran 90 segundos. Los petardos casi siempre con precios inferiores a $10 € .5$ bengalas

\footnotetext{
${ }^{8}$ https://es.wikipedia.org/wiki/Tragedia_de_Heysel. Consultado el 1 de octubre de 2021
} 
rojas, denominadas grandes bengalas de futbol, cuestan 11.19€. ¿Me dicen como se pueden impedir la entrada en nuestro país de todos estos artefactos? ¿o la compra en otros mercados? y no solo se pueden comprar material pirotécnico sino todos los merchandising del futbol.

¡Hasta en Amazon se pueden comprar!

Una vez más hay que recurrir a la educación que hay que inculcar a los niños desde la edad escolar en las familias y en sus ambientes de escolarización y juegos, el respeto hacia los demás, no solo por el peligro que representan estos artefactos en sí mismos, sino por el daño que se pueden producir ellos o sus próximos en la distancia.

El niño de 13 años Guillermo Lázaro murió en 1992 en el estadio de Sarriá tras ser alcanzado por una bengala de uso marítimo que un aficionado lanzó desde el otro extremo del estadio. Aquel cohete se le clavó en el pecho y no se pudo hacer nada por su vida. Durante la reconstrucción de los hechos, el autor del lanzamiento, que fue condenado a seis meses de prisión por un delito de imprudencia temeraria, lloró desconsoladamente.

"Las bengalas no son muy peligrosas, siempre que se usen adecuadamente”, afirma Jesús Asín, director técnico de Pirotecnia Zaragozana. Todo depende de la persona, y un ultra con varios litros de cerveza en el estómago y rodeado de decenas de iguales sumidos en la misma nebulosa es una bomba en potencia. "En un campo de fútbol si lo veo bastante peligroso; las bengalas hay que encenderlas a una distancia de al menos diez metros de otra persona, y esto es imposible en un estadio", explica el experto. Hay que tener en cuenta que este tipo de artefactos alcanzan una temperatura de entre 1.300 y 1.800 grados, según el color. El más frio, por decirlo de alguna forma, es el azul, y el más cálido el rojo, que fue el color dominante en las gradas parisinas del Parque de los Príncipes. "No tiene por qué pasar, pero las chispas prenden con facilidad en la ropa y si caen sobre una pancarta pueden quemarla. Su temperatura es mucho más alta que el fuego", dice Jesús Asin'10.

Tampoco podemos olvidar las manifestaciones racistas. Cada día hay más en los campos de futbol contra los jugadores de raza negra a los que se corea el mono, mono, etc., y que son fenómenos que van directamente ligados a la xenofobia, el racismo y el fascismo de numerosos aficionados pertenecientes a

\footnotetext{
${ }^{9}$ Guillenea, J., : El gran problema que sigue presente en los campos de fútbol. IDEAL 11 marzo 2018, en: https:/www.ideal.es/sociedad/jugar-fuego-20180311005830-ntvo.html. Consultado el 1 de octubre de 2021.

${ }^{10} \mathrm{Ob}$. Cit.
} 
peñas extremistas que son hábilmente utilizadas por partidos políticos europeos de ultraderecha. Todos ellos son grupos violentos que se retroalimentan con frecuencia.

Las invasiones de campos de futbol las ha habido de todo tipo. En general, han sido divertidas cuando eran de personas o animales, perros, gatos, pájaros, hasta un canguro y de personas individuales. Hombres o mujeres vestidos o desnudos. Los numerosos ejemplos de mujeres en bikini, en topless y desnudas, han generado mayor atracción en un mundo deportivo protagonizado por hombres, aunque afortunadamente lo estamos corrigiendo y ahora hay mayor igualdad de géneros y más cuidado en exteriorizar el machismo imperante. En internet se pueden ver ejemplos de todos los casos y muy diferentes.

Sigamos analizando las distintas áreas sociales del futbol en las que brota la violencia de manera espontánea: la violencia contra los árbitros. Existe desde hace muchos años. Hay cientos de entradas en internet sobre la materia entre las que destaco una de un artículo redactado por un grupo de alumnos de la Facultad de Ciencias de la Información (rama periodismo) ${ }^{11}$ donde dice:

Si ponemos en el buscador Google 'agresión árbitro', la búsqueda arroja más de 500.000 resultados. Esa es la triste y cruda realidad. La figura del árbitro está relacionada con la falta de respeto elevada a la máxima potencia. La persona que intenta hacer que las normas se cumplan en cualquier competición es insultada, agredida y utilizada como un saco de boxeo con el que algunos sacian sus múltiples carencias.

La violencia se ha instalado en el fútbol de formación y los últimos episodios ponen en el punto de mira a los progenitores de los chavales. Entrenadores y árbitros denuncian que es un problema cultural y social: los niños se educan desde la violencia por_culpa de los padres. La creación de proyectos que eduquen, la formación de los chicos y sancionar y denunciar más, las claves para erradicar esta lacra.

También quiero prestar atención a la violencia en el futbol de formación, en el futbol de simples aficionados infantiles y juveniles. En este caso puedo aportar mi propia experiencia, obtenida al presenciar simples encuentros infantiles en los que participaba uno de mis sobrinos en las instalaciones deportivas del barrio de la Concepción de Madrid. Al principio supongo serían infantiles, pero ya entonces el espectáculo fue aterrador: los padres insultaban a árbitros por

${ }^{11}$ Varios: Árbitros: las víctimas del deporte. Periódico universitario UCM en la web 2.0. Consultado el 3 de octubre de 2021. 
sus decisiones; al entrenador porque no sacaba a sus hijos, el Cristiano Ronaldo o el Messi de la competición; a los otros padres... y, en frecuentes ocasiones, he visto a los niños llorando y diciendo a sus padres que se callaran y no discutieran y donde las madres eran igual de violentas o más que los padres tanto en competiciones masculinas como en femeninas.

En realidad yo, que nada tenía que ver en el asunto, me preguntaba y ahí dejo la reflexión, si en realidad esos niños hacen deporte o sufren muchísimo en esas competiciones cuyo objetivo por parte de los padres (machotes, ellos, e incluyo a las madres si los dos tenían ese comportamiento) es proyectarse en sus hijos para desbordar la agresividad que llevan dentro. Muchos críos se sentían incómodos con la actitud de sus padres, presionados por una exigencia más en su vida. Seguro que preferirían ir a casa a estudiar, porque desde luego no se llevarían un disgusto así ni con tres suspensos. Otros chavales, sin embargo, se crecían ante la agresividad de sus progenitores, asimilando la triste lección de que la violencia conlleva el reconocimiento de su entorno social. Tampoco hay ninguna autoridad para poner orden en semejantes encuentros, pues los árbitros quedan relegados a meros receptores de todo tipo de insultos, sin lugar a dudas el mejor lugar para aprender tacos que no habías oído, como me pasó en la única ocasión que mi padre me llevó a un partido de fútbol sin ninguna trascendencia, cuando tenía 7 años, un Real Madrid - Granada en el estadio de Chamartín tras el cual volví a casa intentando no olvidarme de palabras que allí oí por primera vez en mi vida. Y los entrenadores tampoco tiene autoridad ni libertad para llevar a cabo las acciones que consideren oportunas, en función de sus conocimientos técnicos ${ }^{12}$.

Por cierto que no sé lo que sucederá en otros países, pero aquí detrás de cada español hay un seleccionador nacional o un entrenador mejor que los Zidane o Luis Enrique. Da igual que sea albañil o economista, barrendero que médico..., a la hora de hacer el equipo que ganaría lo que se juegue, la suya sería la alineación correcta y pasa como con las normas arbitrales, nadie se las conoce, pero todos critican la decisión arbitral y lo mismo la forma física o mental de los jugadores, ¡nadie como ellos!

Volvemos a insistir, la EDUCACIÓN es fundamental en todos los órdenes de la vida, desde en la comida al juego, el saber ganar o perder es denotativo del nivel intelectual de la persona independiente de su vida profesional.

12 Consultar MUNDO DEL ARBITRAJE: Y a la violencia contra los árbitros, ¿cómo la llamamos? martes, 18 de diciembre de 2018. https://mundodelarbitraje.blogspot.com/2018/12/ yla-violencia-contra-los-arbitros-como.html. Consultado 3 octubre 2021. CANTON, E., y otros: Estudio de la violencia contra el árbitro en el fútbol regional y de formación:

https://www.cop-cv.org/db/cke_uploads/files/Violencia\%20f\%C3\%BAtbol\%20\%C3\%A1rbitros \%20E.Cant\%C3\%B3n.pdf. Consultado 3 octubre 2021. 
Solo recordar las peleas entre jugadores ahora, llamadas tanganas o tánganas, que tampoco favorecen en nada al fútbol como deporte y donde se hace muy complicado hacer y aplicar las normas correctas de castigos y redacción de las correspondientes actas arbitrales.

En esta situación los medios de comunicación de masas contribuyen de manera muy notable a crear este ambiente, calentando a las aficiones con sus artículos y comentarios sobre los errores arbitrales, sobre las supuestas malas alineaciones, sustituciones a deshora, etc., etc., y no sigo porque el siguiente punto está dedicado a los derbis.

\section{LOS DERBIS}

Según el Diccionario de la Lengua Española, publicado por la Real Academia Española ${ }^{13}$, el origen de la palabra es inglés y se refiere a la famosa carrera de caballos, fundada por el conde de Derbi y en su primera acepción es una competición hípica..., pero en la segunda es: Encuentro, por lo común futbolístico, entre dos equipos cuyos seguidores mantienen constante rivalidad, casi siempre por motivos regionales o localistas. En mi opinión, esta definición queda un poco anticuada porque en la actualidad deben incluirse los internacionales.

Es casi imposible que no se celebren partidos de futbol casi todos los días, lo que ya esta originando las críticas de los jugadores a los que literalmente matan con los entrenamientos y los partidos de las ligas nacionales, partidos amistosos, en verano y antes de empezar las temporadas, copas de muy distinto signo, encuentros de selecciones nacionales, y diversas copas también que no hacen sino engrosar los derechos audiovisuales de las organizaciones internacionales como la UEFA y que para conocimiento ya se han creado en todo el mundo. Los derbis son acontecimientos habituales.

Un dato curioso para comenzar a hablar de las federaciones internacionales de fútbol es que la Organización de las Naciones Unidas (ONU) está integrada por 192 estados, mientras que la Federación Internacional de Fútbol Asociación (FIFA) cuenta con un total de 211 federaciones nacionales que están afiliadas. Este dato da idea de la importancia que se le da a la ONU y de la que se le da a la FIFA.

Para darnos una idea de cómo están los derbis distribuidos por todo el mundo, en Europa, bajo el amparo de la UEFA, hay 54 países; algunos como España con 24 clásicos, aunque en otro lugar se consideran 27.

\footnotetext{
${ }^{13}$ Diccionario de la Lengua Española. Real Academia Española. 23 ed. 2014. P.729.
} 


\begin{tabular}{|c|c|c|c|c|c|}
\hline Organismo & Siglas & $\begin{array}{c}\text { Año } \\
\text { creación }\end{array}$ & Sede & Ámbito & Miembros \\
\hline $\begin{array}{c}\text { Federation } \\
\text { International de } \\
\text { Football } \\
\text { Association } \\
\text { As }^{14}\end{array}$ & FIFA & 1904 & $\begin{array}{l}\text { Zurich } \\
\text { (Suiza) }\end{array}$ & Mundial & 209 \\
\hline $\begin{array}{c}\text { Union of } \\
\text { European } \\
\text { Football } \\
\text { Association } \\
\text { As }\end{array}$ & UEFA & 1954 & $\begin{array}{l}\text { Nyon } \\
\text { (Suiza) }\end{array}$ & Europa & \\
\hline $\begin{array}{c}\text { Confédération } \\
\text { Africaine de } \\
\text { Football }^{16} \\
\end{array}$ & $\mathrm{CAF}$ & 1957 & $\begin{array}{l}\text { El Cairo } \\
\text { (Egipto) }\end{array}$ & África & 54 \\
\hline $\begin{array}{l}\text { Asian Footbal } \\
\text { Confederation }^{17}\end{array}$ & $\mathrm{AFC}$ & 1954 & $\begin{array}{c}\text { Kuala } \\
\text { Lumpur } \\
\text { (Malasia) }\end{array}$ & Asia & 47 \\
\hline $\begin{array}{l}\text { Confederation del } \\
\text { Norte, Centro } \\
\text { América y el } \\
\text { Caribe Asociación }^{\text {de Futbol }}{ }^{18} \\
\end{array}$ & CONCACAF & 1961 & $\begin{array}{l}\text { Miami } \\
\text { (Florida) }\end{array}$ & $\begin{array}{c}\text { Norte y } \\
\text { Centroamérica } \\
\text { y Caribe }\end{array}$ & 41 \\
\hline $\begin{array}{c}\text { Confederación } \\
\text { Sudamericana de }^{\text {Futbol }{ }^{19}}\end{array}$ & CONMEBOL & 1916 & $\begin{array}{c}\text { Luque } \\
\text { (Paraguay) }\end{array}$ & Sudamérica & 10 \\
\hline $\begin{array}{l}\text { Oceania Football } \\
\text { Confederation }^{20}\end{array}$ & OFC & 1966 & $\begin{array}{l}\text { Auckland } \\
\text { (Nueva } \\
\text { Zelanda) }\end{array}$ & Oceanía & 11 \\
\hline
\end{tabular}

Si consultamos las páginas dedicadas por Wikipedia a los Clásicos del fútbol de España, así se denomina la página, nos remite a 27 páginas para cada derbi, algunos como Madrid y Barcelona tienen dos páginas.

Voy a poner un ejemplo de un derbi de menor importancia, el asturiano, frente a un Barcelona - Español o un Real Madrid-Barcelona o un MadridAtlético de Madrid. El periódico más difundido en papel, en Asturias es La

\footnotetext{
${ }^{14} \mathrm{https}: / /$ www.fifa.com/

15 https://es.uefa.com/

16 https://www.cafonline.com/

${ }^{17} \mathrm{https}: / / \mathrm{www}$. the-afc.com/

$18 \mathrm{https}: / / \mathrm{www}$. concacaf.com/

${ }^{19} \mathrm{https}: / / w w w . c o n m e b o l . c o m /$

${ }^{20}$ https://www.oceaniafootball.com/
} 
Nueva España que dedicó el día anterior al derbi local entre el Real Oviedo Club de Futbol y el Real Sporting de Gijón Club de Futbol, el 8 de octubre de 2021, 9 páginas al derbi y 4 al resto de deportes de las 72 del periódico. El día del derbi, el 9 de octubre, 21 página al asunto, 9 al resto de los deportes y publicó en total 80 páginas. El día de después, el 10 de octubre, dedicó al derbi 11 páginas y 6 al resto de los deportes, de un total de 64 . Pero es que el día de después, o sea el 11 de octubre, dedicó 8 paginas al encuentro, 13 a deportes (recordemos que era lunes) de un total de 64 que editó. Lo podemos ver resumido en el siguiente cuadro:

\begin{tabular}{|c|c|c|c|}
\hline Día & Paginas derbi & Resto deportes & Total periódico \\
\hline $\mathbf{8}$ & 9 & 4 & 72 \\
\hline $\mathbf{9}$ & 21 & 9 & 80 \\
\hline $\mathbf{1 0}$ & 11 & 6 & 64 \\
\hline $\mathbf{1 1}$ & 8 & 13 & 64 \\
\hline
\end{tabular}

El día 12 también dedicó 3 páginas al derbi, pero ya no me parecen significativas.

En el mundo hay 10 clásicos importantes donde, con frecuencia, se producen actos violentos $^{21}$, son los siguientes:

\section{Real Madrid-Barça (España)}

El derbi por excelencia del fútbol español. La rivalidad entre Madrid y Barça va más allá de fronteras. Está entre los tres acontecimientos deportivos más importantes del mundo.

\section{Boca-River (Argentina)}

Es el "Superclásico" del fútbol argentino, se enfrentan los dos equipos más populares del país. Llegan a movilizar a grandes masas de aficionados.

\section{Liverpool-Manchester United (Inglaterra)}

Derbi en el noroeste de Inglaterra entre los "red devils" y los "reds", una de las rivalidades deportivas más importantes del país británico.

\section{Milan-Inter (Italia)}

El derbi de la ciudad de Milán, también conocido como "Derby della Madonnina", es uno de los partidos más importantes y con mayor rivalidad en la Serie A.

\footnotetext{
${ }^{21} \mathrm{https}$ :/es.besoccer.com/noticia/los-10-clasicos-mas-importantes-del-mundo-119088.
} 


\section{Independiente-Racing (Argentina)}

El "clásico" de Avellaneda entre los dos equipos de la ciudad es más que un partido de fútbol. Es el segundo en importancia tras el RiverBoca.

\section{Manchester United-Manchester City (Inglaterra)}

El derbi de Manchester es el partido que representa a los dos clubes de la ciudad, el City y el United. Se hicieron aún más intensos cuando Guardiola y Mourinho coincidieron como rivales en sus banquillos.

\section{Real Madrid-Atlético de Madrid (España)}

Desde los últimos años, el derbi madrileño paraliza Europa y se vive con gran pasión e intensidad.

\section{Sevilla-Betis (España)}

El derbi por excelencia en la ciudad de Sevilla. Se ha convertido en la rivalidad más popular y pasional en el fútbol español y en Andalucía.

\section{Chivas de Guadalajara-América (México)}

Este partido es el "clásico" del fútbol mexicano entre los dos equipos más populares del país. Además son las ciudades más pobladas, Guadalajara y Ciudad de México, respectivamente.

\section{Bayern-Borussia Dortmund (Alemania)}

El derbi entre los dos equipos por excelencia de Alemania, que también es denominado "Der Klassiker". Su rivalidad es bastante reciente, puesto que se están repartiendo los últimos títulos de la Bundesliga.

Todos estos encuentros deportivos implican unas prevenciones de seguridad muy costosas para el país y las ciudades en las que se disputan, aplicando todas las medidas antiviolencia legales posibles para neutralizar a las aficiones que, cada vez, obligan más a los clubes y a los jugadores a usar medios de mayor protección. Recuerdo como hace unos años los jugadores llegaban en sus propios vehículos al campo de futbol y ahora van en un solo autobús, con todo tipo de protección policial y, pese a estas medidas, los violentos rompen las lunas del mismo y, en algún caso, han herido a algún jugador. Otra prueba más de la violencia que se ha recrudecido, puesto que ahora tienen que ir escoltados por la policía desde el hotel de concentración, rodeado de vallas y de policía a caballo con tanquetas etc., como vemos en las imágenes que se difunden por las televisiones, como si de presidentes de gobierno o jefes de estado se tratase. 


\section{LA NEFASTA INFLUENCIA DE LOS LLAMADOS MEDIOS DE COMUNICACIÓN DE MASAS}

Digo nefasta porque en mi opinión los medios son un elemento catalizador de los enfrentamientos entre aficionados y policía. Dicho así suena muy mal, pero con el periodismo escrito y con el audiovisual, repitiendo una y otra vez que si se cometen errores arbitrales y olvidando que los árbitros son, como el resto de los mortales seres humanos y que tienen derecho a equivocarse (por supuesto incluyo también a las árbitras. No me gusta confundir el sexo con el género gramatical, las personas de buena voluntad que no buscamos tres pies al gato, incluimos a ambos. De hecho, estoy hablando de futbolistas y a nadie se le habrá pasado por la cabeza excluir a los integrantes del futbol masculino).

Siempre se ha dicho que la buena educación se demostraba en la mesa, añadiría que no solo en la mesa sino, y mucho más, en el comportamiento con los demás. Ampararse en la masa para insultar a las árbitras, como hace unos días una profesional con 17 años manifestaba en las televisiones que a ella los insultos machistas ya sabía cómo manejarlos, pero si eso se lo hacen a una que tenga 13 u otra edad cualquiera y que no sepa manejar esas situaciones, la pueden frustrar de por vida. La joven protagonista de los insultos poseía una madurez digna de ejemplo, cualidad que, por supuesto, no le llevó a ningún plató de televisión para ser entrevistada, pese a tener una ideas muy claras, una notable personalidad y una frescura elegante con un perfecto conocimiento de hablar ante un micrófono, pero, eso sí, no iba mostrando nada de su cuerpo y no manifestaba nada en relación con el sexo, las influencias que tan de moda se han puesto en este mundo un poco loco y donde, por decir y repetir sandeces, pasan a ser denominadas influencers.

Lo mismo que pongo de manifiesto la cobardía de ampararse en la masa para apedrear a las fuerzas del orden, agredirlos cuando pueden ser los padres de cualquier joven que está tirando objetos arrojadizos a dichas fuerzas. Lo he vivido en la Facultad con una alumna cuyo padre era capitán de la Policía Nacional a caballo y ella estudiante.

¿No nos podemos parar a pensar que la policía en general está pagada por todos los españoles para respetar la libertad de todos y no para recibir pedradas?. Está para salvaguardar la libertad de los peatones que circulan por la calle paseando con su familia, o haciendo posible que un inválido pueda salir a tomar el sol, o sacando a sus hijos al parque a que se relacionen con otros niños y jueguen, en lugar de pasarse horas solos ante los videojuegos o viendo un canal infantil. ¿Por qué hay que agredirlos? De verdad que no lo comprendo y tampoco lo admito, tenemos que tener presente que se están jugando la vida por poner orden entre esas bestias, que no se muestran como personas. Algunos de estos 
violentos van pasados de alcohol y drogas y otros simplemente manifiestan su rencor contra personas que son funcionarios y a los que supongo lo que menos les apetece es dar golpes, porque no estudian para eso, ni resulta agradable agredir para defenderte, lo cual hace que, como todo ser humano, al ser agredido intentes defenderte. Repito no es un entretenimiento deseable, más bien indeseable.

Volviendo a los medios de comunicación, la competencia por tener las máximas audiencias hace que las informaciones tengan exclusivas que a veces son inventadas solo para llamar la atención y congregar a millones de oyentes o telespectadores.

Con la llegada de los diarios digitales se ha aumentado el mercado de noticias de forma muy importante, pero hay que señalar algo fundamental y es que, para ser el primero en dar la noticia, no se comprueban las fuentes y en más de una ocasión se produce lo que ahora se denominan noticias falsas, los modernos periodistas las denominan fake news (algunos son tan modernos y tienen tan altísimo nivel de inglés que no dicen Bob Dylan, sino Bob Dailan. Oído en una emisora nacional por el autor de estas líneas).

Lamentablemente no he oído ninguna estación que llame a la calma, que solicite tranquilidad, una llegada de los equipos sin bengalas, ni apedreamiento de lunas, sino educación y respeto, que ya bastante nerviosos están los equipos teniendo en cuenta los recursos económicos que se están jugando en cada partido, las posibles lesiones, etc., como para que, por añadidura, les rompan las lunas, no vean por las bengalas, ni con el auxilio de los motoristas que custodian los autobuses de los dos equipos para abrirles paso y dejar que lleguen al campo donde se celebra el encuentro con cierto nerviosismo añadido.

\section{LAS NUEVAS TÉCNICAS DE COMUNICACIÓN POR MÓVIL}

No puedo resistirme a no hablar de los nuevos elementos de comunicación por teléfono móvil o tablets como Facebook y WhatsApp, ya anticuado para la juventud, pero sí muy actuales Twitter, Instagram, y Telegram, es decir los medios de comunicación que denominamos redes sociales.

Desgraciadamente, todos ellos, por lo general, se utilizan en los acontecimientos futbolísticos para encizañar, divulgar noticias falsas, insultar, provocar, llamar a la agresión, etc., y a celebrar manifestaciones y otras acciones reprobables.

Veamos unos ejemplos: 
433 (@433) - Como la gran mayoría de cuentas en esta red social, comenzó como un espacio para compartir videos y fotografías del fútbol alrededor del mundo, pero poco a poco se convirtió en una plataforma indispensable para todos los amantes de este deporte. Cuentan con más de 18 millones de seguidores ${ }^{22}$.

Me interesa más éste:

Football Memes Insta (@footballmemesinsta)-Si lo que quieres es divertirte en cada jornada del fútbol europeo, no hay duda de que esta cuenta es para ti. Actualmente cuentan con 1.6 millones de seguidores y se caracterizan por burlarse de todo lo posible ${ }^{23}$.

Y esta tampoco se queda atrás, lanzando rumores sobre contrataciones, todo sin comprobar ${ }^{24}$ :

$@$ @footyheadlines: FootyHeadlines = filtraciones. Esta página web (y por ende su cuenta de instagram) es todo menos información oficial. Deben tener una red de informantes en distintas marcas y fábricas, porque realmente no se les escapa una. Les encanta también lanzar rumores sobre contratos de clubes con distintas marcas. ¡Poco fina pero muy informativa!

Y no sigo por la falta de espacio y porque no considero oportuno hacer propaganda de estos fabricantes de noticias.

\section{CONCLUSIONES}

En primer lugar son necesarias toneladas de educación y respeto. Primero educación entre los padres, en las familias, en el colegio, entre los niños, entre los jóvenes, entre los adultos, en los campos de futbol y en los alrededores, entre los jugadores, los aficionados, los equipos técnicos de los clubes, etc.

Respeto hacia las decisiones de los árbitros y entrenadores, jcon que facilidad se cesa a un entrenador de fútbol!, los padres con los hijos, que no están para gritarles en los partidos de sus respectivas categorías que son niños y se pueden

\footnotetext{
${ }^{22}$ La negrita es mía. https://www.tudn.com/futbol/las-conocias-las-7-cuentas-de-instagram-quetodo-amante-del-futbol-debe-seguir-fotos

${ }^{23} \mathrm{Ob}$. cit.

${ }^{24} \mathrm{https} / / /$ medium.com/fc-lab/15-cuentas-de-instagram-para-todo-futbolero-a4fe0b76bf36
} 
equivocar que no están tampoco en un examen de selectividad, que simplemente están en un partido de fútbol.

Las desigualdades económicas entre los ingresos de un jugador y los de un simple albañil son tan brutales que no son sino injustas. Cierto que el futbolista puede ingresar tantos millones por tantos derechos que puede salirle al club hasta gratis, pero no se trata de eso, lo que debemos buscar es una justa repartición de los salarios, que todos puedan vivir como mínimo dignamente y que tampoco para enriquecimiento de los clubes se haga jugar a los futbolistas todos los días de la semana con campeonatos, copas, amistosos, trofeos, etc., que los jugadores son humanos y necesitan también descansar.

Recordar que hay que evitar que todos los conflictos se resuelvan con cargas de la policía Ya sé que este no sería nuestro mundo pero lo que tenemos que pensar es en un futuro SIN VIOLENCIA, de ningún tipo y que los propios aficionados aparten a sus amigos o colegas del equipo en situaciones de enfrentamientos o peleas, por pasarse de alcohol o porque piensen que el árbitro ha querido favorecer al otro equipo a propósito, cosa que no digo que no se pueda producir y de hecho se ha producido amañando partidos, pero no suele ser frecuente entre auténticos profesionales.

Por último, escuchar y oír más, ponerse en el papel del otro, de modo que hagamos el esfuerzo de comprender al resto de los aficionados que nos rodean en un campo de fútbol y asistir para pasar un rato agradable, entretenido, que unas veces se gana y otras se pierde y en eso consiste la vida en general, los deportes como actividad a ver o jugar y con el fútbol en particular.

Lo veo muy difícil, pero aquí quedan estas reflexiones, pensamientos y hechos para que cada uno obtenga sus conclusiones lo más enriquecedoras posibles para su personalidad.

Y termino invocando una expresión que reúne todos los elementos modernos, ingleses y propios del deporte del fútbol: fair play en todos los ámbitos que lo rodean. 


\section{APÉNDICES}

\begin{tabular}{|c|c|c|c|c|c|c|c|c|c|c|}
\hline 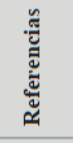 & 怘 & 응 & 立 & $\stackrel{\varrho}{\Xi}$ & $\stackrel{\infty}{-1}$ & ఏ్ & สี & ก & Э્ন & $\begin{array}{l}\text { :్ } \\
\text { ఫ్రి }\end{array}$ \\
\hline $\begin{array}{l}\stackrel{\dot{\Xi}}{\Xi} \\
\text { 导 }\end{array}$ & ๙̆ & $\stackrel{\infty}{\varrho}$ & 亏े & ऽ̆ & ळे & $\vec{\Delta}$ & 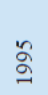 & $\bar{\Xi}$ & ळ & ఏ \\
\hline 是 & $\overrightarrow{\vec{i}}$ & $\begin{array}{l}\text { a } \\
\stackrel{i}{1}\end{array}$ & $\overrightarrow{\vec{i}}$ & $\stackrel{\infty}{\stackrel{\sim}{\sim}}$ & ڤे & ते & त्ં & ठे & तิ่ & $\stackrel{\circ}{\circ}$ \\
\hline 递它 & $\stackrel{\infty}{\stackrel{\leftrightarrow}{4}}$ & 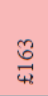 & 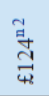 & $\underset{\vec{\psi}}{\stackrel{\pi}{\vec{\alpha}}}$ & $\frac{\overrightarrow{\mathrm{I}}}{\overrightarrow{4}}$ & $\underset{\vec{\psi}}{\overrightarrow{0}}$ & $\frac{8}{4}$ & $\stackrel{\text { ڤે }}{\leftrightarrow}$ & 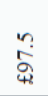 & 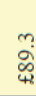 \\
\hline 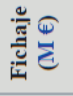 & สี & $\underset{\mathbb{\Psi}}{\stackrel{\infty}{\Psi}}$ & $\begin{array}{l}\tilde{W} \\
\stackrel{\omega}{\omega} \\
\tilde{\omega}\end{array}$ & 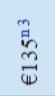 & $\begin{array}{l}\overrightarrow{0} \\
\vec{\Psi} \\
\mathbb{\Psi}\end{array}$ & $\begin{array}{l}\tilde{c} \\
\tilde{\omega} \\
\tilde{\omega}\end{array}$ & $\hat{\vec{\Psi}}$ & $\begin{array}{l}\circ \\
\stackrel{0}{*}\end{array}$ & $\stackrel{n}{\frac{\pi}{\Psi}}$ & $\begin{array}{l}\frac{0}{0} \\
\frac{0}{w}\end{array}$ \\
\hline 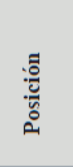 & 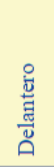 & 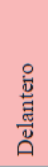 & 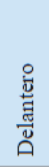 & 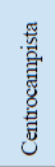 & 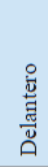 & 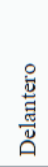 & 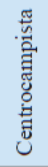 & 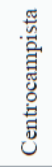 & 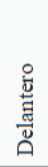 & 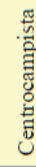 \\
\hline 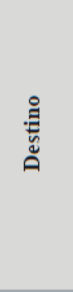 & 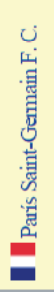 & 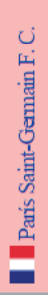 & 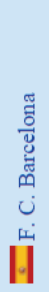 & 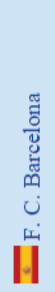 & 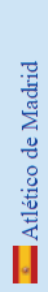 & 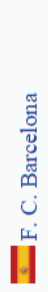 & 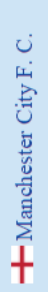 & 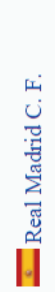 & 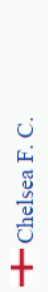 & 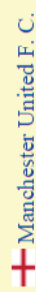 \\
\hline 总 & 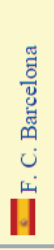 & 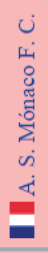 & 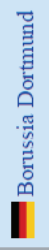 & 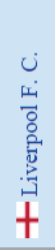 & 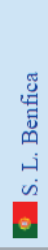 & 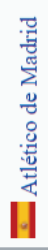 & 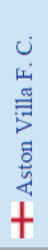 & 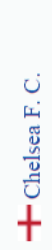 & 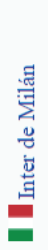 & 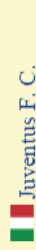 \\
\hline 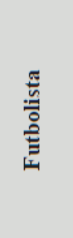 & 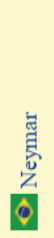 & 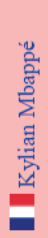 & 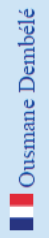 & 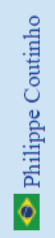 & 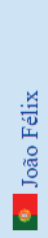 & 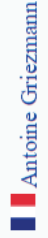 & 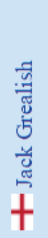 & 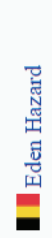 & 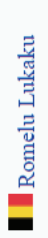 & 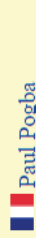 \\
\hline$\simeq$ & -1 & $N$ & & & in & 0 & $r$ & $\infty$ & a & $\stackrel{\varrho}{ }$ \\
\hline
\end{tabular}


FRANCISCO JOSÉ MONTES FERNÁNDEZ

\begin{tabular}{|c|c|c|c|c|c|c|c|c|c|c|c|}
\hline 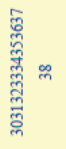 & 요 & $\frac{7}{F}$ & 举 & 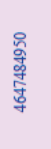 & సี & 哌 & $\begin{array}{l}\text { ô } \\
\text { ồ } \\
\text { hi }\end{array}$ & $\overrightarrow{8}$ & ๕్రి & 迢 & 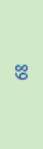 \\
\hline$\stackrel{\text { }}{\stackrel{9}{ }}$ & 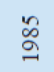 & $\begin{array}{l}\mathscr{2} \\
\stackrel{-}{\Omega}\end{array}$ & $\stackrel{\stackrel{\infty}{g}}{ }$ & ડ̆ & ळ & ¿্ণ & ळ & $\vec{\circ}$ & ڤ్ & $\stackrel{\varrho}{\Omega}$ & 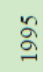 \\
\hline$\stackrel{m}{\stackrel{n}{\sim}}$ & $\stackrel{\infty}{\stackrel{\sim}{\sim}}$ & ઠेે & $\stackrel{\circ}{\stackrel{\sim}{\sim}}$ & $\stackrel{m}{\vec{i}}$ & $\stackrel{\text { ¿े }}{\circ}$ & ते & $\overrightarrow{\text { )े }}$ & ثे & 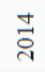 & ڤे & 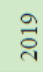 \\
\hline$\underset{\leftrightarrow}{\stackrel{\leftrightarrow}{~}}$ & $\begin{array}{c}\infty \\
\substack{\infty \\
\leftrightarrow}\end{array}$ & 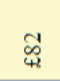 & 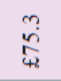 & $\begin{array}{l}\overrightarrow{\vec{n}} \\
\stackrel{2}{\phi}\end{array}$ & 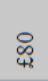 & 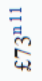 & 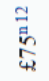 & $\stackrel{n}{4}$ & $\underset{t}{n}$ & $\underset{4}{T}$ & $\stackrel{1}{4}$ \\
\hline 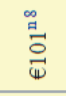 & 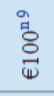 & ষ̊ய & \& & 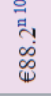 & ô & $\stackrel{2}{\infty}$ & 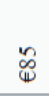 & $\begin{array}{l}+\dot{+} \\
\underset{\Phi}{\Psi}\end{array}$ & 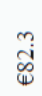 & $\underset{\mathbb{\Psi}}{\mathscr{\Psi}}$ & $\underset{\mathbb{W}}{\stackrel{0}{\mathbb{W}}}$ \\
\hline 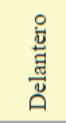 & 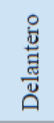 & 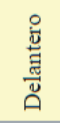 & 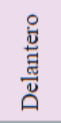 & 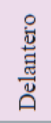 & 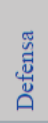 & 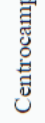 & 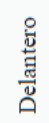 & 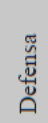 & 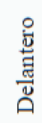 & 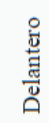 & 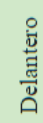 \\
\hline 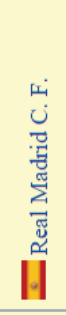 & 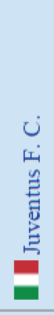 & 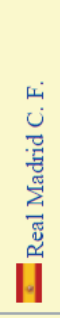 & 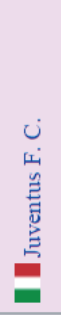 & 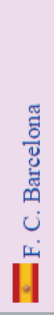 & 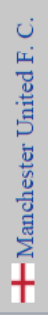 & 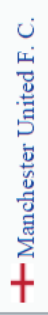 & 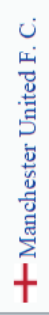 & 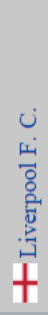 & 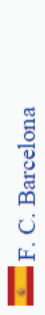 & 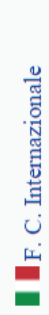 & 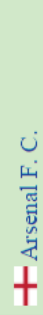 \\
\hline 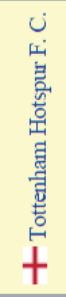 & 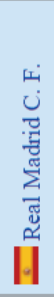 & 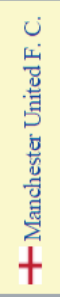 & 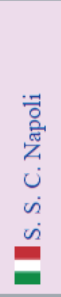 & 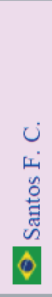 & 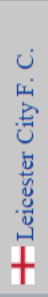 & 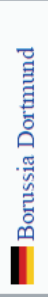 & 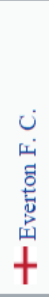 & 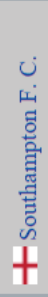 & 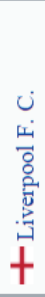 & 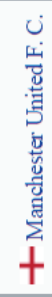 & $\begin{array}{l}\dot{0} \\
\text { v } \\
0 \\
0 \\
:\end{array}$ \\
\hline 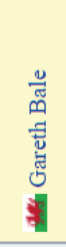 & 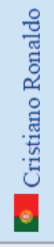 & 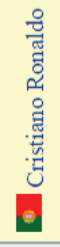 & 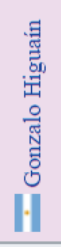 & 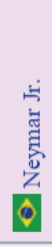 & 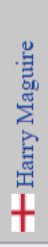 & 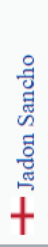 & 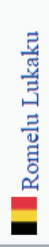 & 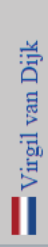 & 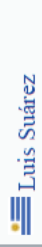 & 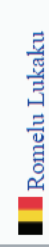 & 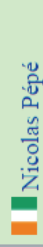 \\
\hline$\Rightarrow$ & $\approx$ & 9 & \pm & 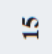 & 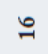 & \multicolumn{2}{|c|}{$=$} & 9 & సి & \multicolumn{2}{|c|}{$\bar{T}$} \\
\hline
\end{tabular}




\begin{tabular}{|c|c|c|c|c|c|c|c|c|c|c|c|}
\hline 8) & R & 气ิ & 高 & Бे & ڤ్ & 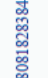 & 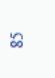 & ळ్ & $\infty$ & ळి & Бे \\
\hline な & $\stackrel{2}{\circ}$ & $\stackrel{5}{S}$ & よे & $\begin{array}{l}\infty \\
\stackrel{\infty}{\Omega}\end{array}$ & ஃे & बे & 亏̆ & Бे & ஃ̊ & 品 & $\stackrel{\infty}{\Omega}$ \\
\hline$\stackrel{\infty}{\stackrel{\sim}{\sim}}$ & ठें & $\overrightarrow{\mathrm{d}}$ & ర్తి & $\stackrel{+}{\vec{i}}$ & ڤे & 茫 & $\stackrel{\vec{े}}{\circ}$ & $\stackrel{\sim}{\stackrel{n}{\sim}}$ & ర్రి & $\stackrel{\infty}{\stackrel{\sim}{\sim}}$ & శ్రి \\
\hline$\underset{+\infty}{\stackrel{0}{i}}$ & 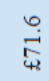 & $\begin{array}{l}0 \\
\stackrel{0}{0} \\
\stackrel{+}{+}\end{array}$ & $\stackrel{\circ}{\overbrace{4}}$ & & 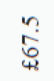 & 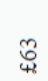 & 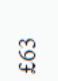 & 令 & 品 & 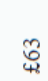 & : \\
\hline 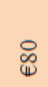 & 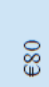 & 站 & E & 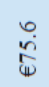 & 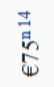 & $\stackrel{\frac{n}{*}}{\stackrel{n}{*}}$ & 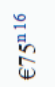 & $\stackrel{+}{\mathbb{W}}$ & $\underset{\mathbb{W}}{\mathbb{N}}$ & $\stackrel{?}{*}$ & $\stackrel{\circ}{*}$ \\
\hline 茪 & 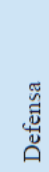 & 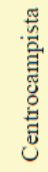 & 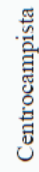 & 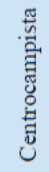 & $\begin{array}{l}\text { J } \\
\text { जू } \\
\text { صू }\end{array}$ & 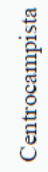 & 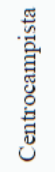 & 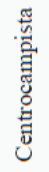 & 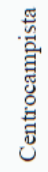 & 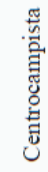 & 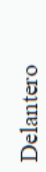 \\
\hline 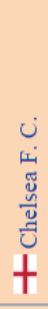 & 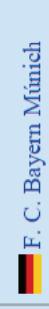 & 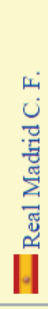 & 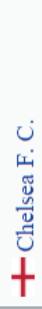 & 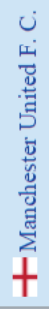 & 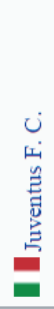 & 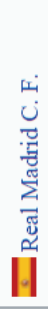 & 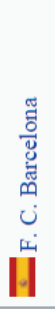 & 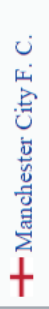 & 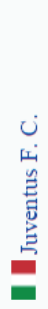 & 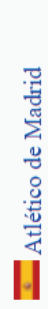 & 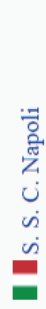 \\
\hline 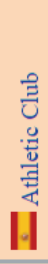 & 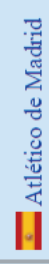 & 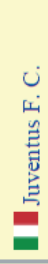 & 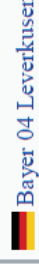 & 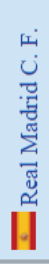 & 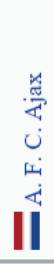 & 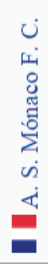 & 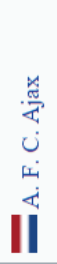 & 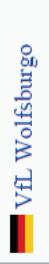 & 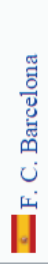 & 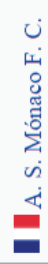 & $\begin{array}{l}\dot{u} \\
\dot{0} \\
0 \\
0 \\
= \\
0\end{array}$ \\
\hline 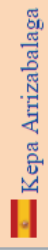 & 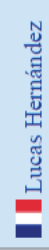 & 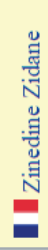 & 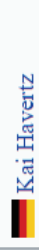 & 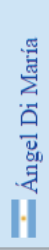 & 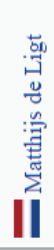 & 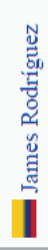 & 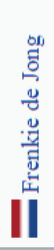 & 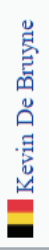 & 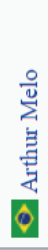 & 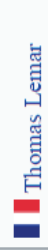 & 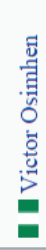 \\
\hline & & $\stackrel{4}{4}$ & $\stackrel{8}{\sim}$ & $\hat{\imath}$ & \multicolumn{3}{|c|}{$\stackrel{\text { ని }}{ }$} & $\vec{m}$ & ల్ & \multicolumn{2}{|c|}{$m$} \\
\hline
\end{tabular}




\begin{tabular}{|c|c|c|c|c|c|c|c|c|c|c|}
\hline ลే & 岁 & ஃ & 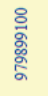 & $\stackrel{\Xi}{\Xi}$ & $\cong$ & 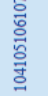 & $\stackrel{\circ}{\stackrel{\circ}{-1}}$ & $\begin{array}{l}\bar{\Xi} \\
\text { 홍 }\end{array}$ & $\Xi$ & $\cong$ \\
\hline $\overrightarrow{\stackrel{\circ}{\sigma}}$ & ڤ̆ & $\vec{\Omega}$ & Љ̊ & ऽ̆ & ১ু & $\stackrel{\text { 心 }}{\stackrel{\sigma}{\sigma}}$ & $\stackrel{2}{2}$ & $\begin{array}{l}\infty \\
\stackrel{\infty}{\sim}\end{array}$ & 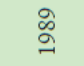 & ঃ \\
\hline ळे & ڤ్ & $\stackrel{\infty}{\stackrel{i}{\sim}}$ & ठे̀ે & $\overrightarrow{\tilde{c}}$ & $\stackrel{\infty}{\stackrel{\infty}{\sim}}$ & $\stackrel{m}{\vec{i}}$ & ڤे & $\stackrel{\sim}{\tilde{a}}$ & $\stackrel{\infty}{\stackrel{\infty}{c}}$ & ठे \\
\hline ڤે & స్ర & 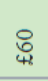 & 苗 & 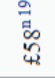 & $\tilde{\omega}$ & $\tilde{\kappa}$ & 岕 & $\frac{n}{4}$ & 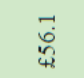 & 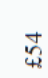 \\
\hline 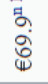 & : & $\begin{array}{l}\infty \\
\stackrel{0}{0} \\
\mathbb{w}\end{array}$ & $\underset{\mathbb{W}}{\stackrel{\infty}{*}}$ & $\begin{array}{l}n \\
\tilde{0} \\
\psi\end{array}$ & $\tilde{\psi}$ & 先 & $\underset{\mathbb{W}}{\mathbb{t}}$ & $\underset{\mathbb{W}}{\mathbb{t}}$ & $\begin{array}{l}\overrightarrow{8} \\
\vec{\Phi}\end{array}$ & $\widetilde{乛}$ \\
\hline 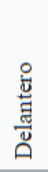 & 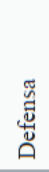 & 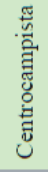 & 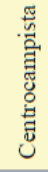 & 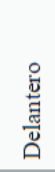 & 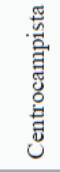 & 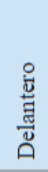 & 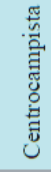 & 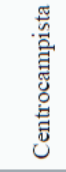 & 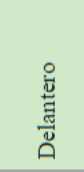 & 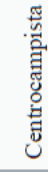 \\
\hline 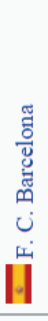 & 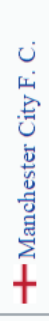 & 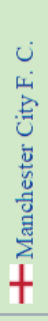 & 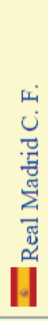 & 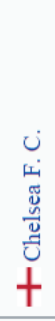 & 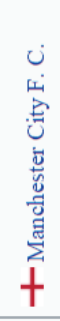 & 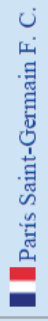 & $\begin{array}{l}u \\
\dot{u} \\
\tilde{y} \\
\tilde{y} \\
\tilde{U} \\
+ \\
+\end{array}$ & 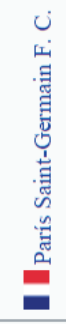 & 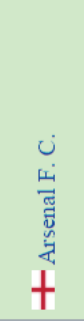 & 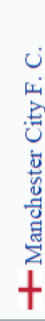 \\
\hline 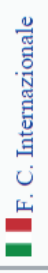 & 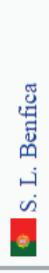 & 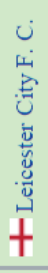 & 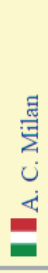 & 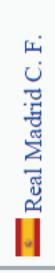 & 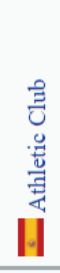 & 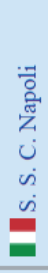 & 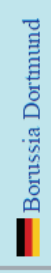 & 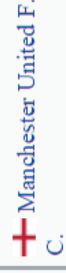 & 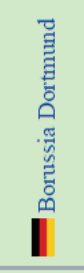 & 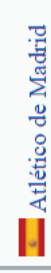 \\
\hline 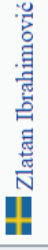 & 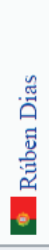 & 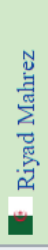 & 党 & 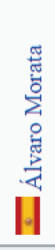 & 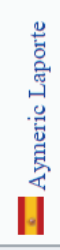 & 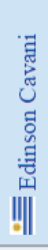 & 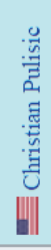 & 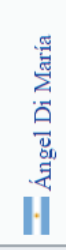 & 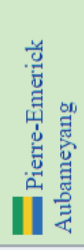 & 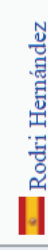 \\
\hline ల్ల & ల్ల & m & $\underset{ల}{\infty}$ & ले & \& & $F$ & & & ₹ & if \\
\hline
\end{tabular}




\begin{tabular}{|c|c|c|c|c|c|c|c|c|c|}
\hline$\Xi$ & $\cong$ & $\stackrel{\vec{\Xi}}{\underline{\Xi}}$ & 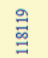 & ‡ & $\vec{\Xi}$ & ีี & $\stackrel{\nexists}{\nexists ~}$ & ఫే & $\infty$ \\
\hline ఏे & よ̃ & ळ & 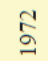 & $\stackrel{\circ}{\stackrel{2}{ }}$ & ஃ & ळ̆ & $\vec{\sigma}$ & $\begin{array}{l}\stackrel{\circ}{9} \\
\stackrel{2}{\circ}\end{array}$ & ஃ \\
\hline 髉 & $\stackrel{\infty}{\vec{\sim}}$ & $\stackrel{\sim}{\tilde{i}}$ & ঃ্் & त् & ڤे & $\stackrel{\infty}{\stackrel{\sim}{\sim}}$ & $\overrightarrow{\stackrel{i}{A}}$ & $\stackrel{m}{\stackrel{n}{\Lambda}}$ & ర్రి \\
\hline $\overrightarrow{\widehat{s}}$ & $\begin{array}{l}\text { त्: } \\
\text { 心 } \\
\leftrightarrow\end{array}$ & 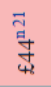 & $\stackrel{\tilde{\dddot{q}}}{0}$ & $\underset{\vec{n}}{\stackrel{n}{n}}$ & $\begin{array}{l}\infty \\
\stackrel{\infty}{\infty} \\
\leftrightarrow\end{array}$ & 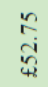 & Зิ & $\overrightarrow{\vec{n}}$ & 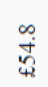 \\
\hline శ్లి & 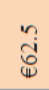 & 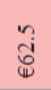 & $\frac{\pi}{\overline{0}}$ & 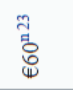 & 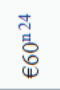 & $\stackrel{8}{.}$ & 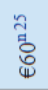 & 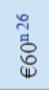 & 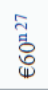 \\
\hline 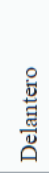 & 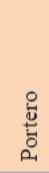 & 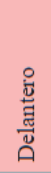 & 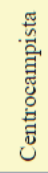 & 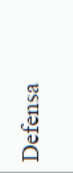 & 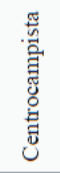 & 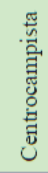 & 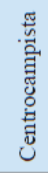 & 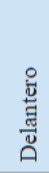 & 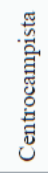 \\
\hline 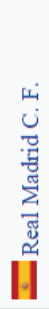 & 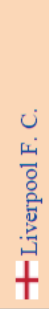 & 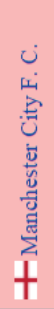 & 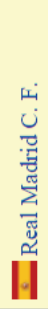 & 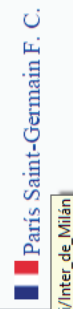 & 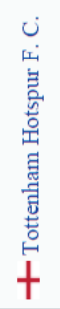 & 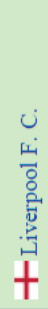 & 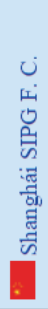 & 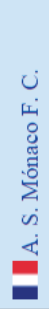 & 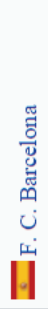 \\
\hline 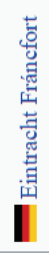 & 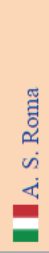 & 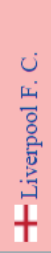 & 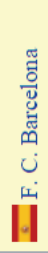 & 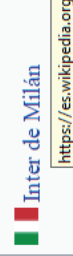 & 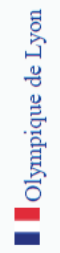 & 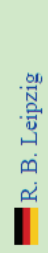 & 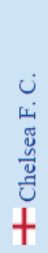 & 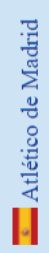 & 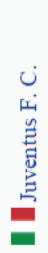 \\
\hline 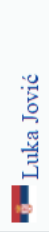 & 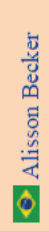 & 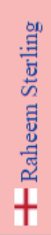 & 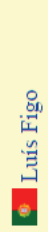 & 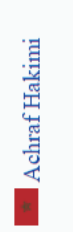 & 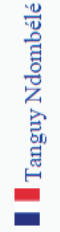 & 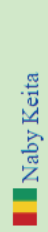 & 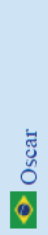 & 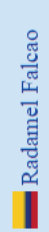 & 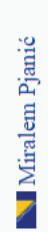 \\
\hline & f & $\stackrel{\infty}{+}$ & $q$ & \\
\hline
\end{tabular}


